\title{
University Student Expectations of Confidentiality when Disclosing Information to their Professors
}

\author{
Gregory E. Harris ${ }^{1} \&$ Stephanie Dalton ${ }^{1}$ \\ ${ }^{1}$ Faculty of Education, Memorial University, St. John's, Newfoundland \\ Correspondence: Greg Harris, Faculty of Education, G. A. Hickman Building, Memorial University, P. O. Box \\ 4200, St. John's, Newfoundland.
}

Received: October 31, 2013

Accepted: January 8, 2014 Online Published: January 23, 2014

doi:10.5539/hes.v4n1p43

URL: http://dx.doi.org/10.5539/hes.v4n1p43

\begin{abstract}
The purpose of this study was to explore university students' expectations of confidentiality when they make disclosures to their university professors. A secondary purpose was to consider if students have a higher expectation of confidentiality when talking with Psychology professors versus professors in other disciplines. Students were asked to complete online survey scenarios assessing their expectations for confidentiality during various student-professor exchanges. Independent variables included professor discipline and disclosure location. Results suggested that students maintain a high degree of confidentiality expectations when making disclosures to their professors, especially when these disclosures happen in the professor's office. Implications for teaching and future research are discussed.
\end{abstract}

Keywords: confidentiality, teaching, post-secondary institutions, student informed consent, student-professor relationship

\section{Introduction}

Assurances of confidentiality have long been a core condition of relationships in which members must share personal information or take risks in the context of those relationships. Such is the case for professional relationships, such as counseling, in which a client must be able to disclose personal information while trusting that the counselor will not breach confidentiality. Research supports confidentiality in the context of such professional helping relationships and clients have come to expect such confidentiality from their counselors and allied mental health professionals (Donner, Vande-Creek, Gonsiorek, \& Fisher, 2008; Youggren \& Harris, 2008). However, we know very little about confidentiality expectations when it comes to other types of professional relationships, such as relationships between students and professors. The purpose of this study was to explore the degree of university students' expectations of confidentiality when they make disclosures to their university professors. A secondary purpose was to consider if students have a higher expectation of confidentiality when talking with Psychology professors versus professors in other disciplines. By understanding students' expectations for confidentiality, professors may be in a better position to meet those expectations and to engage in dialogue around those expectations (Dalton \& Harris, 2010). This research also has several implications for the ethical practice of teaching and has potential unique implications for Psychology professors who are also Registered Psychologists.

\subsection{Positive Teacher-Student Relationships}

There is support that learning and personal growth are facilitated, at least in part, through a positive relationship (Hattie, 2009; Roorda, Koomen, Spilt, \& Oort, 2011). Research has illustrated several implications associated with positive student-teacher relationships including gains in classroom engagement and cooperation as well as enhanced academic outcomes (Battistich, Schaps, \& Wilson, 2004; Birch \& Ladd, 1997; Klem \& Connell, 2004). Secure relationships can evoke a sense of psychological safety and such a relationship can help to facilitate credibility, risk taking, motivation, introspection, and focused attention among the relationship members (Faye \& Sharpe, 2008; Hattie, Liew, Chen, \& Hughes, 2010; Corey, 2008; Roorda et al., 2011). Such conditions have been identified as key considerations in educational psychology, counseling, and effective teaching literatures (Delaney, Johnson, Johnson, \& Treslan, 2010; Faye \& Sharpe, 2008; Hattie, 2009; Liew et al., 2010; Corey, 2008; Roorda et al., 2011). Trust is a key condition of such positive relationships. Without a sense of trust, such relationships would be extremely difficult, if not impossible, to establish. 
Research has suggested that university students (e.g., nursing students, education students) do place a high degree of value on having positive relationships with their professors. Bergman and Gaitskill (1990) reported that nursing students in their study actually rated characteristics of their relationship with their instructors as being more important than even the professional competence of their instructors. In this study, an open and honest relationship was highlighted. Wong (2005) emphasizes that "the student-teacher relationship is at the heart of the learning-teaching process" (p. 1). In her study, fifth year education students reported that professors' abilities to create a "safe and trusting" classroom environment were key (p. 4). Delaney et al. (2010) studied the characteristics of effective teachers from the point of view of university students at a large Canadian university and found that students placed high emphasis on "respectful" and "professional" professors. Both of these categories used themes such as "trustworthy" (p. 5), "trust", and "honesty" (p. 17).

\subsection{Psychology Professors and Student-Professor Confidentiality}

Researchers claim that the obligation surrounding confidentiality accepted by academic psychologists has been overlooked and that students' perceptions of confidentiality has received even less exploration (Tabachnick, Keith-Spiegel, \& Pope, 1991; Hogan \& Kimmel, 1992). Hogan and Kimmel (1992) suggest that students believe Psychology professors are caring and more skilled in helping than other professors, and that students with "special vulnerabilities" are drawn to Psychology courses in the hopes of gaining a better understanding of their current circumstance and acquiring more suitable coping strategies. Psychology courses often deal with sensitive issues not broached by other fields (Hogan \& Kimmel, 1992). These topics may inspire disclosures that would not otherwise be revealed in other courses (Haney, 2004). It may also be assumed that if one is currently teaching and is identified as a psychologist by one's students (or self identifies as a Registered Psychologist) then those students would expect their teacher to follow the same ethical principles as other practicing psychologists. Research implies that professors, by wearing the title of "psychologist" may unknowingly influence student expectations of confidentiality. For instance, students may assume their Psychology professors have clinical training and are, therefore, professionally equipped to handle very intimate problems revealed by their students (Haney, 2004; Hogan \& Kimmel, 1992; Tantleff-Dunn, Dunn, \& Gokee, 2002).

\subsection{Confidentiality and Teaching Standards}

Ethical principles associated with teaching have also been established. For example, the Society for Teaching and Learning in Higher Education has developed the Ethical Principles in University Teaching. Principle Six, Confidentiality, highlights the following: "Student grades, attendance records, and private communications are treated as confidential materials, and are released only with student consent, or for legitimate academic purposes, or if there are reasonable grounds for believing that releasing such information will be beneficial to the student or will prevent harm to others" (p. 3). This highlights the importance of student-professor confidentiality and places a great deal of expectation on professors in this regard. Indeed, the section goes on to state: "This principle suggests that students are entitled to the same level of confidentiality in their relationships with teachers as would exist in a lawyer-client or doctor-patient relationship. Violation of confidentiality in the teacher-student relationship can cause students to distrust teachers and to show decreased academic motivation..." (p. 3).

Post-secondary institutions across Canada have adopted rules and regulations prioritizing the protection of students' personal information (e.g., FIPPA, 1996; ATIPPA, 2002). However, the weight of the information outlined in such policies is given to keeping student records confidential. In addition, research and academic literature focused on student confidentiality has tended to be focused on areas such as student records (Essex, 2004; Holub, 2003) versus student personal disclosures to teachers or professors. Little emphasis is placed on the importance of private communications between a professor and his/her student and even less research has been devoted to whether students' perceptions differ based on the subject being taught by a professor and the setting of the disclosure. Having said that, many places of higher education, including universities, have adopted frameworks or guidelines that focus on teaching and learning. These are often aspirational in nature and help professors and students understand key considerations in effective teaching and learning, such as confidentiality owed to students.

\section{Methods}

As noted, the purpose of this study was to explore student expectations of confidentiality between themselves and their university professors, bringing particular focus to professors teaching Psychology. The study examined whether a difference exists in student perceptions of confidentiality with regard to professors of Psychology versus professors teaching in other areas (i.e., Education, Engineering, and English). We also studied student perceptions of confidentiality with professors across different settings: after class, in the professor's office, or 
during an encounter off campus grounds.

\subsection{Hypotheses}

The study hypotheses included the following:

H1: Students will maintain the highest confidentiality expectations for Psychology professors versus Education, Engineering, and English professors.

H2: Students will maintain the highest confidentiality expectations for disclosures made during a scheduled meeting in the professor's office versus after class or off campus grounds.

H3: Sex will not account for differences in student expectations for confidentiality.

\subsection{Procedures}

We recruited participants from a large Atlantic Canadian university using several university department or student society listserves (e.g., Psychology, Education, Engineering, English). Participants received a brief email from the listserve in their respective department or society outlining the research and asking for their participation. Students had the option to delete the message, if they were not interested in participating, or to click a link at the bottom of the e-mail, which took them to the informed consent form and study measures. Participants could then complete the measures (described below) and submit them electronically using an online survey system. Data was stored on this system.

\subsection{Measures and Variables}

Two measures were included in the study. The first measure was a self constructed survey that asked participants to rate their expectations of confidentiality in each of 12 scenarios. Participants were given the following general directions:

Please rate each scenario with a percentage score (i.e., $0 \%$ to $100 \%$ ) regarding your expectation that the professor in each scenario will maintain your confidentiality. For example, if you were absolutely expectant that a professor would maintain your confidentiality then you would likely score the scenario with $100 \%$. However, if you were absolutely not expectant that the professor would maintain your confidentiality then you would likely score the scenario with $0 \%$. If you held an equal expectation between the professor maintaining your confidentiality and the professor not maintaining your confidentiality then you would likely score the scenario as $50 \%$. Your actual scores can range anywhere from $0 \%$ to $100 \%$.

The 12 scenarios were developed to test our two key independent variables: professor discipline (i.e., Psychology, Education, English, and Engineering) and disclosure location (i.e., after class, professor's office, and off campus grounds). The three core scenarios were as follows, with only the professor discipline being changed to make up the other nine scenarios. Four versions of the questionnaire were constructed in order to counterbalance the variable discipline.

You are a student in a Psychology class with Professor Michaels and you disclose personal information about yourself to Professor Michaels after the other students have left the classroom. What are your expectations that Professor Michaels will maintain confidentiality with your personal information?

You arrange a meeting with your Psychology professor, Professor Black, in the professor's office on campus. During the meeting you disclose personal information. What are your expectations that Professor Black will maintain confidentiality with your personal information?

You meet your Psychology professor, Professor Avery, by chance, after school off campus grounds. You disclose personal information during this interaction. What are your expectations that Professor Avery will maintain confidentiality with your personal information?

The second measure was a demographic questionnaire consisting of a range of questions measuring mainly nominal and ratio data. Participants were asked about their age, sex, year of full time study, ethnicity, major/minor, number of credits completed to date, as well as number of credits completed in Psychology, Education, Engineering, and English.

\section{Results}

\subsection{Participants}

Three hundred and thirty nine participants returned surveys. After removing incomplete surveys, 226 surveys were included in the current study. Participants were $22.54 \pm 4.12$ years of age $(n=226)$. One hundred and thirty 
six $(60.18 \%)$ were female, 88 (38.94\%) were male, and two did not report their sex. Two hundred and thirteen students reported data for their year of study: first year $(23 ; 10.8 \%)$; second year $(31 ; 14.6 \%)$; third year ( 38 ; $17.8 \%)$; fourth year $(42 ; 19.7 \%)$; fifth year $(44 ; 20.7 \%)$; sixth year $(24 ; 11.3 \%)$; and seventh year or higher $(11$; 5.2\%). Two hundred and fifteen participants reported a major: Business/Accounting/Commerce (39; 18.1\%); English/Linguistics (10; 4.7\%); Engineering (99; 46\%); Science such as Math, Biology, and Pharmacy (19; 8.8\%); Education (30;14\%); and Psychology/Behavioural neuroscience $(18 ; 8.4 \%)$. Of the participants reporting number of Psychology credits completed, 120 (57.14\%) reported completing at least one credit in Psychology.

Table 1. Demographics

\begin{tabular}{lc}
\hline Age (mean, SD) & $22.54 \pm 4.12$ years \\
\hline Sex (frequency and percentage for female) & $136 ; 60.18 \%$ \\
\hline Year of study (frequency and percentage for first year) & $23 ; 10.8 \%$ \\
\hline $\begin{array}{l}\text { Major (frequency and percentage for } \\
\text { Business/Accounting/Commerce) }\end{array}$ & $39 ; 18.1 \%$ \\
\hline
\end{tabular}

\subsection{Confidentiality}

Disciplines. Students did report the highest confidentiality expectations for Psychology professors in all three scenarios (the only exception to this was in scenario two where Psychology and Education professors were scored as equivalent) (see Tables 1, 2, and 3). Having said that, overall mean differences tended to be relatively small. In our repeated measures ANOVA, we interpreted the Lower-Bound statistic due to potential violations with Sphericity. For scenario one, discipline was significant $(F(3,175)=3.99, p=.047)$. Pairwise significant differences were noted between Psychology and English (.001) and Education and English (.014). Sex was also noted as significant in the equation for scenario one $(\mathrm{F}(1,175)=5.73, \mathrm{p}=.018)$, with females reporting higher confidentiality expectations for professors in all disciplines (see Table 1). No significant results were found for scenario two for discipline or sex. It is noteworthy that a similar trend was observed in that female students reported higher confidentiality expectations for professors in all disciplines (see Table 2), albeit this was not significant. For scenario three, discipline was significant $(\mathrm{F}(1,175)=4.57, \mathrm{p}=.034)$. Pairwise significant differences were noted between Psychology and Engineering (.001) and Education and Engineering (.008). Sex was also noted as significant for scenario three $(F(1,175)=3.94, p=.049)$, with females reporting higher confidentiality expectations for professors in all disciplines (see Table 3 ).

Table 2. After class disclosure scenario across disciplines

\begin{tabular}{llll}
\hline Discipline & Male $(\mathrm{n}=60)$ & Female $(\mathrm{n}=117)$ & Total $(\mathrm{n}=177)$ \\
\hline Psychology & $83.25 \%(23.54)$ & $90.17 \%(15.81)$ & $87.82 \%(19.01)$ \\
Education & $81.83 \%(23.88)$ & $89.83 \%(15.28)$ & $87.12 \%(18.96)$ \\
Engineering & $82.33 \%(23.17)$ & $88.46 \%(16.13)$ & $86.38 \%(18.97)$ \\
English & $81.25 \%(23.93)$ & $88.12 \%(16.81)$ & $85.79 \%(19.72)$ \\
\hline
\end{tabular}

Mean \% (SD)

Table 3. Professor office disclosure scenario across disciplines

\begin{tabular}{llll}
\hline Discipline & Male $(\mathrm{n}=58)$ & Female $(\mathrm{n}=118)$ & Total $(\mathrm{n}=177)$ \\
\hline Psychology & $90.43 \%(19.09)$ & $93.73 \%(13.82)$ & $92.64 \%(15.78)$ \\
Education & $89.74 \%(19.20)$ & $94.07 \%(12.98)$ & $92.64 \%(15.39)$ \\
Engineering & $89.83 \%(18.66)$ & $92.63 \%(15.34)$ & $91.70 \%(16.51)$ \\
English & $89.57 \%(19.25)$ & $92.50 \%(15.19)$ & $91.53 \%(16.64)$ \\
\hline
\end{tabular}

Mean \%(SD) 
Table 4. Off campus disclosure scenario across disciplines

\begin{tabular}{llll}
\hline Discipline & Male $(\mathrm{n}=59)$ & Female $(\mathrm{n}=118)$ & Total $(\mathrm{n}=177)$ \\
\hline Psychology & $65.34 \%(32.75)$ & $74.73 \%(26.07)$ & $71.60 \%(28.72)$ \\
Education & $65.85 \%(32.39)$ & $72.32 \%(26.70)$ & $70.16 \%(28.80)$ \\
Engineering & $64.75 \%(33.61)$ & $69.44 \%(27.38)$ & $67.88 \%(29.59)$ \\
English & $66.02 \%(31.77)$ & $70.20 \%(26.66)$ & $68.81 \%(28.44)$ \\
\hline
\end{tabular}

Mean \% (SD)

Scenarios. Across all four disciplines, students reported the highest expectations for confidentiality when the disclosure was made in the professor's office, with the second highest degree of expectation being given to after class disclosure (see Tables 4, 5, 6, and 7). This trend was significant in our ANOVA for each discipline: Psychology $(F(1,182)=94.37, p<.001)$, Engineering $(F(1,188)=106.43, p<.001)$, Education $(F(1,189)=106.52$, $\mathrm{p}<.001)$, and English $(\mathrm{F}(1,193)=111.29, \mathrm{p}<.001)$. In all scenarios, female students reported higher confidentiality expectations for professors (see Tables 4, 5, 6, and 7).

Table 5. Discipline of psychology by disclosure scenario

\begin{tabular}{llll}
\hline Scenario & Male $(\mathrm{n}=62)$ & Female $(\mathrm{n}=120)$ & Total $(\mathrm{n}=182)$ \\
\hline After Class & $82.98 \%(23.63)$ & $89.50 \%(17.67)$ & $87.28 \%(20.08)$ \\
Professor's Office & $90.89 \%(18.57)$ & $93.00 \%(16.17)$ & $92.28 \%(17.00)$ \\
Off Campus & $63.79 \%(33.09)$ & $74.11 \%(26.74)$ & $70.59 \%(29.38)$ \\
\hline
\end{tabular}

Mean \% (SD)

Table 6. Discipline of engineering by disclosure scenario

\begin{tabular}{llll}
\hline Scenario & Male $(\mathrm{n}=67)$ & Female $(\mathrm{n}=121)$ & Total $(\mathrm{n}=188)$ \\
\hline After Class & $81.25 \%(24.22)$ & $88.18 \%(16.09)$ & $85.71 \%(19.60)$ \\
Professor's Office & $89.52 \%(18.24)$ & $92.27 \%(15.26)$ & $91.29 \%(16.39)$ \\
Off Campus & $64.28 \%(32.81)$ & $69.00 \%(27.72)$ & $67.29 \%(29.63)$ \\
\hline
\end{tabular}

Mean \% (SD)

Table 7. Discipline of education by disclosure scenario

\begin{tabular}{llll}
\hline Scenario & Male $(\mathrm{n}=69)$ & Female $(\mathrm{n}=120)$ & Total $(\mathrm{n}=189)$ \\
\hline After Class & $81.52 \%(23.97)$ & $90.00 \%(15.15)$ & $86.90 \%(19.23)$ \\
Professor's Office & $90.29 \%(18.61)$ & $94.08 \%(12.88)$ & $92.70 \%(15.29)$ \\
Off Campus & $64.41 \%(32.48)$ & $72.70 \%(26.65)$ & $69.67 \%(29.10)$ \\
\hline
\end{tabular}

Mean \% (SD)

Table 8. Discipline of English by disclosure scenario

\begin{tabular}{|l|l|l|l|}
\hline Scenario & Male $(\mathrm{n}=70)$ & Female $(\mathrm{n}=123)$ & Total $(\mathrm{n}=193)$ \\
\hline After Class & $82.00 \%(22.97)$ & $87.84 \%(16.82)$ & $85.72 \%(19.43)$ \\
\hline Professor's Office & $90.29 \%(18.00)$ & $92.00 \%(15.45)$ & $91.37 \%(16.40)$ \\
\hline Off Campus & $65.29 \%(31.24)$ & $69.63 \%(26.71)$ & $68.05 \%(28.43)$ \\
\hline
\end{tabular}

Mean \% (SD) 


\section{Discussion}

Confidentiality is an important ingredient for the establishment of trusting and effective relationships. Such relationships have been shown to positively impact student motivation and learning (Faye \& Sharpe, 2008; Hattie, 2009; Roorda et al., 2011). Results of the current investigation suggest that students have high expectations of their professors in maintaining confidentiality when it comes to student and professor exchanges. This is especially apparent for exchanges happening in professors' offices and following classes (i.e., as consistent with Hypothesis two). Interestingly, students still held fairly high expectations for confidentiality even when such exchanges happened off university grounds during chance encounters. This highlights the importance of professors maintaining confidentiality when it comes to information shared by their students. Indeed, this is highlighted in teaching ethics documents such as the Ethical Principles in University Teaching by the Society for Teaching and Learning in Higher Education. Post-secondary education institutions should strongly consider adopting guidelines that highlight the importance of such confidentiality expectations. Professors and faculty alike are often left with little guidance and direction when it comes to such student-professor conversations, as much of the literature and documentation around confidentiality associated with student materials is directed at such things as student records. As seen in the current study, students have expectations of confidentiality when it comes to student-professor exchanges as well.

From an academic discipline perspective, professors of Psychology, Education, Engineering, and English were all held to a high expectation for confidentiality by students in this study. Participants held the highest expectations for Psychology and Education faculty. In line with hypothesis one (H1), we expected Psychology professors to be held to a higher standard. Research has highlighted that students may place high expectations on their Psychology professors when it comes to confidentiality expectations. For example, students see their Psychology professors as more caring than other professors (Hogan \& Kimmel, 1992) and Psychology courses often deal with sensitive issues that may facilitate disclosures that would not otherwise be revealed in other courses (Haney, 2004). Students may also believe their Psychology professors have clinical training and are equipped to address personal problems disclosed by their students (Haney, 2004; Hogan \& Kimmel, 1992; Tantleff-Dunn et al., 2002). It is possible that Education professors were held to a higher standard as well due to the helping orientated nature of this discipline and perhaps an expectation that Education professors would be aware of the importance of confidentiality in a teaching and learning context. Research has also found that effective teachers are seen as being trustworthy (Delaney et al., 2010).

Inconsistent with hypothesis three (H3), we found that sex was a significant variable in our analyses. Female students held higher expectations of confidentiality as compared to male students in every scenario. This again has important implications for professors and post secondary institutions. Professors should keep in mind that when talking with female students, those students may hold even higher expectations for confidentiality, and professor confidentiality views should be shared with these students, if possible, prior to personal disclosures. Future research should explore student confidentiality expectations with a gender-based lens.

Given the complexity of confidentiality in a teaching context, one possible solution is that Psychology professors, along with other types of professors, discuss confidentiality, and its limitations, with their students. Professors could explain their views on confidentiality and could even discuss certain limitations (e.g., potential harm to student or others) during exchanges with students or at the start of courses. Information on confidentiality, including limitations, could also be included as a brief description on course syllabi. This upfront disclosure is in line with informed consent practices. Professors often vary in their degree of willingness to engage with students around personal or sensitive topics. It is important for all professors to still recognize the potential for student disclosures and to have a plan to deal with those disclosures in a way that preserves the student-professor relationship.

\section{Study Limitations}

The current study employed a convenience sampling strategy and included a high degree of engineering students, limiting the generalizability of the findings. As well, the data were markedly skewed and there were unequal group sizes when considering sex in the various scenarios. Accordingly, we interpreted the lower bound statistic, which is most conservative. Few of the participants reported being Psychology majors, but the majority of participants did complete coursework in Psychology. Taken together, the current study offers some very interesting preliminary data on an understudied topic, but results should be interpreted within the context of the above noted limitations.

\section{Conclusions}

University students have a high expectation that their professors will maintain confidentiality when it comes to 
student disclosures. Although this expectation may be slightly higher when it comes to Psychology professors, student expectations for confidentiality remain high across a wide array of academic disciplines. Professors need to understand these expectations and be prepared to address these expectations in order to ensure a safe and trusting learning environment.

\section{References}

Access to Information and Protection of Privacy Act, S.N.L. c. A-1.1. (2002).

Battistich, V., Schaps, E., \& Wilson, N. (2004). Effects of an elementary school intervention on students' "connectedness" to school and social adjustment during middle school. The Journal of Primary Prevention, 24, 243-262. http://dx.doi.org/10.1023/B:JOPP.0000018048.38517.cd

Bergman, K., \& Gaitskill, T. (1990). Faculty and student perceptions of effective clinical teachers: An extension study. Journal of Professional Nursing, 6, 33-44. http://dx.doi.org/10.1016/S8755-7223(05)80187-5

Birch, S. H., \& Ladd, G. W. (1997). The teacher-child relationship and early school adjustment. Journal of School Psychology. http://dx.doi.org/10.1016/S0022-4405(96)00029-5

Corey, G. (2008). Theory and practice of counseling and psychotherapy (8th ed.). Brooks/Cole.

Dalton, S., \& Harris, G. E. (2010). Examining student-professor confidentiality: What are the expectations for psychology professors? Morning Watch, 37. Retrieved February 3, 2011, from http://www.mun.ca/educ/faculty/mwatch/Greg_Harris_09.pdf

Delaney, J., Johnson, A., Johnson, T., \& Treslan, D. (2010). Students' perceptions of effective teaching in higher education. Morning Watch, 37. Retrieved September 10, 2013, from http://www.mun.ca/educ/faculty/mwatch/laura_treslan_SPETHE_Paper.pdf

Donner, M. B., VandeCreek, L., Gonsiorek, J. C., \& Fisher, C. B. (2008). Balancing confidentiality: Protecting privacy and protecting the public. Professional Psychology: Research and Practice. http://dx.doi.org/10.1037/0735-7028.39.3.369

Essex, N. L. (2004). Confidentiality and student records: Ten ways to invite legal challenges. Clearing House, 77 , 111-114. http://dx.doi.org/10.1080/00098650409601240

Faye, C., \& Sharpe, D. (2008). Academic motivation in university: The role of basic psychological needs and identity formation. Canadian Journal of Behavioural Sciences. http://dx.doi.org/10.1037/a0012858

Freedom of Information and Protection of Privacy Act, R.S.B.C. c. 165. (1996).

Haney, M. R. (2004). Ethical dilemmas associated with self-disclosure in student writing. Teaching of Psychology. http://dx.doi.org/10.1207/s15328023top3103_2

Hattie, J. (2009). Making learning visible: A synthesis of over 800 meta-analyses relating to achievement. London: Routledge.

Hogan, P. M., \& Kimmel, A. J. (1992). Ethical teaching of psychology: One departments' attempts at self-regulation. Teaching of Psychology. http://dx.doi.org/10.1207/s15328023top1904_1

Holub, T. (2003). College student records: Legal issues, privacy, and security concerns. ERIC Digests. Retrieved November, 2013, from http://eric.ed.gov/?id=ED480467

Klem, A. M., \& Connell, J. P. (2004). Relationships matter: Linking teacher support to student engagement and achievement. Journal of School Health, 74, 262-273. http://dx.doi.org/10.1111/j.1746-1561.2004.tb08283.x

Liew, J., Chen, Q., \& Hughes, J. (2010). Child effortful control, teacher-student relationships, and achievement in academically at-risk children: Additive and interactive effects. Early Childhood Research Quarterly, 25, 51-64. http://dx.doi.org/10.1016/j.ecresq.2009.07.005

Roorda, D. L., Koomen, H. M. Y., Spilt, J. L., \& Oort, F. J. (2011). The influence of affective teacher-student relationships on students' school engagement and achievement: A meta-analytic approach. Review of Educational Research, 81, 493-529.

Society for Teaching and Learning in Higher Education. (n.d.). Retrieved September 15, 2013, from http://www.stlhe.ca/awards/3m-national-teaching-fellowships/initiatives/ethical-principles-in-university-tea ching/

Tabachnick, B. G., Keith-Spiegel, P., \& Pope, K. S. (1991). Ethics of teaching: Beliefs and behaviors of psychologists as educators. American Psychologist. http://dx.doi.org/10.1037/0003-066X.46.5.506 
Tantleff-Dunn, S., Dunn, M. E., \& Gokee, J. L. (2002). Understanding faculty-student conflicts: Students' perceptions of precipitating events and faculty responses. Teaching of Psychology. http://dx.doi.org/10.1207/S15328023TOP2903_03

Wong, P. (2005). Online and face-to-face students' perceptions of teacher-learner interactions: A preliminary examination. Distance Learning, 2(5), 1-7.

Younggren, J. N., \& Harris, E. A. (2008). Can you keep a secret? Confidentiality in psychotherapy. Journal of Clinical Psychology: In Session, 64, 589-600. http://dx.doi.org/10.1002/jclp.20480

\section{Copyrights}

Copyright for this article is retained by the author(s), with first publication rights granted to the journal.

This is an open-access article distributed under the terms and conditions of the Creative Commons Attribution license (http://creativecommons.org/licenses/by/3.0/). 